\title{
KNOWLEDGE BASED MANUFACTURINE SYSTEM
}

\author{
Gideon Halevi ${ }^{1}$ and Kesheng Wang ${ }^{2}$ \\ 'Technion - Israel Institute of Technology; Technion City 32000, ISRAEL. ${ }^{2}$ Department of \\ Production and Quality Engineering, NTNU, N-7491, Norway. E-mail: halev@bezeqint.net \\ and Kesheng.wang@ntmu.no
}

\begin{abstract}
Production management performance relies on data specified by engineers that are neither an economists nor production planners. Therefore, production planning and control becomes a complex task. This paper presents a method where engineer's task is not to make decisions but rather to prepare a "road map". Each user will generate routine that meets his needs at the time of need by using KBMS CAPP. Thereby increase dramatically manufacturing efficiency.
\end{abstract}

Key words: manufacturing; scheduling; capacity planning; shop floor control

\section{INTRODUCTION}

The manufacturing process is a dynamic; conditions are constantly changing and decisions have to be made within a short space in time. It is often preferable to have a decision on hand at the right moment than to seek the optimum decision without any time limit. The better the available relevant data at the right time, the better decision that will be reached. A computer is a tool that can be employed to narrow the gap between the conflictions demands of "time" and "decision". A computer system can store and manipulate large quantity of data in a short period of time. Therefore the computer was accepted enthusiastically by industry as a data processing center. Most computerized application used the methods and algorithms used by manual system, but performing them more often and quicker.

Please use the following format when citing this chapter:

Halevi, Gideon, Wang, Kesheng, 2006, in International Federation for Information Processing (IFIP), Volume 207, Knowledge Enterprise: Intelligent Strategies In Product Design, Manufacturing, and Management, eds. K. Wang, Kovacs G., Wozny M., Fang M., (Boston: Springer), pp. 79-88. 
The real change in thinking and procedure in the manufacturing cycle was the MRP - material requiring planning / material resource planning. The objective of MRP is to plan the activities to be performed in order to meet the goals of the master production schedule.

The logic and mathematics upon which MRP is based is very simple. The gross requirements of the end product for each specific order is compared against on-hand and on-order quantities and then offset by the lead-time to generate information as to when assembly should be started. All items or subassemblies required for the assembly should be available on that date, in the required quantity. Thus, the above computation establishes the gross requirements for the lower level items. The same computation is repeated level by level throughout the entire product structure.

MRP [5] represents an integrated communication and decision support system that supports management total manufacturing business. The use of optimizing techniques drawn from operation research and management science was adapted by MRP. One significant reason why MRP was the technique that was adapted was that it made use of the computer's ability to centrally store and provide access to the large body of information that seemed necessary to run a company. It helped coordinate the activities of various functions in the manufacturing firm such as engineering, production and materials, purchasing, inventory, etc.

The attraction of MRP lay not only in its role as decision-making support, but more important in its integrative role within the manufacturing organization. Several areas of the plan are affected by MRP: production planning and scheduling, quality control, accounting, first line supervision, production labor, and the use to develop plant-wide scheduling.

A closed total working system can be based on MRP, starting with customer order, following by purchasing and sub-contractors order, shop floor scheduling and control, inventory management and control, bookkeeping and accounting. All are dependent activities such that each one is validated by status of the manufacturing system.

\section{INTEGRATED MRP - IMRP}

Integrated MRP is a working strategy where the computer is a working tool and not merely a data retrieval system. [3] It is an innovative strategy that covers all manufacturing stages to one comprehensive unique system. The logic of the system is that there is an objective, i.e. customer order that must be delivered. All activities of the manufacturing cycle are predicted and focused to meet that objective in the most efficient way and they can be performed automatically by using company databases, without human interventions. 
IMRP prescribe what should be purchased, what should be subcontracted and what should be processed in shop. Using company databases a specification for purchasing the item on the list are prepared and sent to preferred suppliers for RFQ. Based on algorithm and suppliers rating data a decision is made.

The logic of the inventory system is that issue and receipt are all predictable. No components are received unless they were ordered, no items are issue unless they serve a specific order, or are needed for assembly or processing of a specific order. No shop-floor activity is performed unless it was scheduled by IMRP. No payment is done unless purchasing order was accepted and the payment terms are met.

All activities validate one another and action decisions are made automatically without manual introversions.

It sound as a perfect system, but unfortunately, IMRP was not a success story. Probably because it was introduced before the IT technology and the data collection systems were available to support its requirements.

Therefore manufacturing turned to other venues. One philosophy believes that production planning and control is very complex: therefore the only way to make such a system effective is to simplify it [4]. This trend proposed systems such as: Just in Time, Lean manufacturing, Agile manufacturing, kanabn, Kaizen, Grourp Technology and cellular manufacturing.

Another philosophy believes that production planning and control is very complex; therefore, there is no chance of developing a system that will solve production problems. Hence, the role of computers should be limited to supplying data while the decisions should be made by peole [1]. Several excellent systems are available. These manufacturing philosophies do not pretend to be integrated systems, and as people make decisions, it is not the SYSTEM fault if a disruption occurs, they are the decision making responsibility.

\section{MANUFACTURING DATA}

No matter what manufacturing strategy is employed it is based on data store in company computer databases. Databases such as: Order file; Product structure; Routing file; Inventory file; Resource file; Production feedback data file.

Data creation and storage is the responsibility of the appropriate discipline. For example: Product structure lists all items composing the product and the links between them. This data is created and stored by 
engineering department. Routing file specifies how each item and assembly is to be produced is created and stored by process planning department.

Each of the appropriate departments will probably consider many options and optimize its decision before introducing the data to the company database.

The data in those files is considered, by its various users, as a reliable, accurate and being what is stated beyond any possibility of doubt. It assumes that it is based on optimum values, validated in the process of inputting the data to the files.

Theoretical production planning and scheduling is actually very simple task. The plant gets orders which define the product, the quantity and delivery dates. The resources of the plants are known, the product bill of material is known. The task of production scheduling is to make sure that the orders will be ready on time, that's all. IMRP and other manufacturing strategy can generate a good operation list. The complexity appears when disruptions encounters, disruptions in the planning stage and in shop floor processing. In many cases disruptions appears due to the nature of the manufacturing data in the company databases.

Although the data is the optimum from the discipline that generated it, it must be remember that it is optimized by criteria of optimization of that of the specific discipline. Each discipline has different optimization criteria. For example, the design criteria are not the same as that of processing, and not that of shop floor control. The criteria of sales are not the same as those of the production management.

The probability of having overall company optimization, by using individual discipline optimization is very low and almost impossible. Especially when the company overall optimization is different than any discipline optimization, it is profit. But none of the individual disciplines, working with perfect local optimization assures company manufacturing meeting its objectives. Each discipline criteria of optimization must match the objective of the discipline. The main objectives are not negotiable they must be met; If they are not met the task solution is not acceptable. However there are several secondary objectives such as: cost, weight, appearance, maintainability, environmental issues etc. that the optimization criterion is a compromise of all of them.

Compromise means that there are several alternative solutions and the one that is in the company database is one of many that is selected by the engineer assigned to the job. Furthermore, in process planning, for example, there are three criterion of optimization: minimum cost; maximum production; and maximum profit. The data does not specify which criterion was selected for the recommended routing. 
Process planning in spite of its importance to the manufacturing cycle, is predominantly labor intensive, depending on experience, skill and intuition of human labor. Dependence on such methodologies often precludes a thorough analysis and optimization of the process and nearly always results in higher than necessary production cost, delays, errors and nonstandardization of processes.

There is time interval between the data creation and the data application. Optimized data is introduced into the databank a long time before its uses; therefore it cannot consider the present state of production. That is the main cause that production management becomes a complex task.

In production planning and scheduling resource overload are created and bottlenecks occur and must be resolved. As the data used was the optimum one, the only way to resolve the situation is to decide priority rules or develop a very complex capacity planning program.

\section{KNOWLEDGE BASE MANUFACTURING - KBMS}

The complexity is not a must [6], it occurs due to the strategy taken; a knowledge based manufacturing strategy will make manufacturing a simple straight forward system.

The objectives of the system are to increase productivity and reduce manufacturing costs. These objectives are the same as those of many other systems. The difference lies in the approach and strategy employed [2]. The Knowledge based manufacturing strategy approach makes use of the following notions:

- There are infinite ways of meeting design objectives.

- In any design about $75 \%$ of the dimensions (geometric shape) are nonfunctional (fillers). These dimensions can vary considerably without affecting the design performance.

- There are infinite ways of producing a product.

- The cost and lead time required to produce a component are functions of the process used.

- Transfer of knowledge between disciplines working to produces a product, should not be by transferring decisions, but rather by transferring alternatives, ideas, options considered, reasoning etc.

- Company database should be "open" and available to all disciplines.

These notions are what any of us does in personal life. For example: If you wish to go from point A to point B you, study the map and plan the optimum route to take. This is the present time decision. However, at another time when you have to move the same way, say, at night you might change 
the route, in winter you probably will look for a route with maximum shelter from the rain. In summer you might choose a route that protects you from the sun. In spring time you might choose a route with nice view. Despite the decision if you run into disruptions, such as a blocked road (bottleneck), red traffic light or with a crowded you might decide that instead of waiting it is better to consult the road map and change the route in order to find a path with no obstacles. Such change is done at each junction. It might be a longer route but it will be faster. The original decision must not prevent one from adapting the new route.

Similar strategy can be applied to production planning and management. The knowledge based manufacturing system proposes to supply each manager with a "road map" which is stored in the company databases, and allow him to deviate from the original processing route while accomplishing the production program assign for a period. Naturally the production program must be practical.

The problem is that by present day technology the manufacturing databases includes only decisions (without revealing why and how they were arrived at) and therefore the "road map" indicates only one path. Naturally the one that make the decision considered many options; alternatives, and optimization methods. To our sorrow all such considerations are lost, and merely decisions are transferred and stored in the company database. What should be done is to capture this available data and store it, instead of letting it go to waste.

The task of the process planner is to select out of the tremendous number of alternatives, the most economical process. The sequence of decisions affects the recommended process and thus can introduce many artificial constrains on the selected process planning.

However, the process planner is neither an economist nor a production planner. Therefore he should not make decisions that are beyond his field of expertise. His task should be to prepare a road map, covering all feasible routings, and let the expert in production planning decide which route to use, in light of order size and plant load at the moment a decision is needed. A product tree (network shown in Fig. 1) is used throughout all the planning steps.

The road map data can be achieved either by the process planner; instead of throwing away his scratch book computation, let him write it down in the spread sheet. Or list the selected routing in the spread sheet format, and use a computer program to fill in the operation time data for other resources. It takes a relative simple program to calculate the operation time based on the process planner computations. The time conversion can be based on resource specifications (such as power); assembly operations can be converted by ratios of manual operation, machine operation or robotics, etc. 
The data ("road map") can be used in many applications: in resource planning, costing, cash flow planning, profit forecasting, budget and management control, master production plan, capacity planning and shop floor scheduling and control, performance measuring decision support system setting delivery date as a function of cost. Each application uses the data in a method fit its needs, but all use one main database.

Alternative routings can be generated by KBMS CAPP program that transformed process planning from a technological into a mathematics decision. Any user can generate a routing, without the assistance of a professional process planner, by setting his parameters, and the computer program will generate the routing.

\begin{tabular}{|c|c|c|c|c|c|c|c|c|c|c|c|}
\hline Pro. & $\begin{array}{l}0 \\
p\end{array}$ & $\begin{array}{l}\mathbf{P} \\
\mathbf{R}\end{array}$ & $\mathbf{n}$ & $\mathrm{nz}$ & w & Ru & K5 & $R 6$ & k7 & R8 & R9 \\
\hline \multirow[t]{5}{*}{932} & 10 & 00 & 3.12 & 3.17 & 368 & 99 & 4.02 & 3.27 & 99 & 99 & 99 \\
\hline & 20 & 00 & 1.15 & 1.2 & 1.71 & 99 & 2015 & 1.3 & 99 & 99 & 99 \\
\hline & 30 & 20 & 1.49 & 1.53 & 203 & 99 & 99 & 1.64 & 99 & 99 & 99 \\
\hline & 40 & 10 & 1.30 & 135 & 1.86 & 1.86 & 22 & 1.45 & 99 & 99 & 99 \\
\hline & 50 & 40 & 1.78 & 1,33 & 1.84 & 90 & 2.18 & 1.43 & 99 & 99 & 99 \\
\hline \multirow{5}{*}{$\mathrm{BP3}$} & 60 & 50 & 1.51 & 1.56 & 2.07 & 99 & 99 & 1.66 & 99 & 99 & 99 \\
\hline & 10 & 00 & 3.12 & 3.17 & 3.68 & 99 & 4.02 & 3.27 & 99 & 39 & 99 \\
\hline & 20 & 10 & 1.5 & 1.2 & 1,71 & 99 & 9.05 & 1.3 & 92 & 99 & 99 \\
\hline & 30 & 20 & 126 & 1.31 & 1.82 & 99 & 99 & 1.41 & 99 & 99 & 99 \\
\hline & 40 & 10 & 1.57 & 1.62 & 2.13 & 2.53 & 247 & 1.72 & 99 & 99 & 99 \\
\hline \multirow{7}{*}{ FB5 } & 50 & 70 & 2.06 & 2,11 & 2,62 & 2.62 & 2.96 & 221 & 99 & 99 & 99 \\
\hline & 10 & 0 & 3.12 & 3.17 & 3.68 & 99 & 4.02 & 3.27 & 99 & 99 & 99 \\
\hline & 20 & 0 & 1.15 & 1.2 & 1.71 & 99 & 2.05 & 1.3 & 93 & 99 & 99 \\
\hline & 30 & 20 & 1.49 & 1.53 & 2.15 & 99 & 99 & 1.64 & 99 & 99 & 99 \\
\hline & 40 & 10 & 1.30 & 1,33 & 1.86 & 1.86 & 2.2 & 1.45 & 99 & 99 & 99 \\
\hline & 50 & 40 & 1.28 & 1.33 & 1.84 & 95 & 2.18 & 1.43 & 99 & 99 & 99 \\
\hline & 60 & 50 & 1.31 & 1.56 & 307 & 99 & 99 & 1.66 & 39 & 99 & (9) \\
\hline \multirow{4}{*}{ FHa } & 70 & 60 & 144 & 1.49 & 2.00 & 99 & 99 & 1.59 & 99 & 99 & 99 \\
\hline & 10 & 0 & 3.12 & 3.17 & 3.68 & 99 & 4.02 & 3.27 & 99 & 99 & 92 \\
\hline & 20 & 10 & 1.15 & 12 & 1.4 & 99 & 2.05 & 1.3 & 99 & 90 & 92 \\
\hline & 30 & 20 & 1.26 & 1.31 & 1.82 & 99 & 99 & 1.41 & 99 & 99 & 99 \\
\hline \multirow{3}{*}{188} & 40 & 10 & 2.06 & 2.11 & 2,62 & 2,62 & 2,96 & 221 & 99 & 99 & 99 \\
\hline & 30 & 0 & 99 & 99 & 99 & 99 & 99 & 99 & 1.45 & 1.72 & 1.96 \\
\hline & 20 & 10 & 99 & 99 & 99 & 99 & 99 & 92 & 1.45 & 1.72 & 99 \\
\hline \multirow[t]{2}{*}{ (19) } & 10 & 0 & 99 & 99 & 99 & 99 & 99 & 99 & 2.03 & 2.33 & 2.57 \\
\hline & 20 & 10 & 99 & 99 & 99 & 93 & 99 & 99 & 191 & 1,85 & 99 \\
\hline $\mathrm{ClO}$ & 10 & 00 & 99 & 99 & 99 & 99 & 99 & 99 & 286 & 3.12 & 99 \\
\hline
\end{tabular}

Figure 1. The road map time content.

The definition of the mathematical problem is as follows: Given a road map (Fig. 1) which lists operations to be performed; a list of available resources; and the time to process each operation on each resource. A decision is required as to which resource to use for each operation; in what sequence in order to generate an optimum routing. The operations in the list are not arranged according to any reasonable sequence. However, some operations must precede others or join with others. These constraints are stated in the road map in the PR (priority) column. 
Extra expenses and time should be added to cover extra when moving from one resource to another. These extra expenses are called "penalty". Thus the penalty is for a batch, and is a function of the batch quantity to be produced. Naturally, for different quantities and constraint a different routing will result.

\section{EXAMPLES OF USING THE ROAD MAP}

The process planner recommends the best routing to produce a product. The question is: what is best process? Is it best from maximum production or for minimum cost? Is it independent of quantity? Is best to generate profit to the company?

To examine those questions we used the road map KBMS CAPP program to generate 22 process alternatives of one item. The alternatives are shown in Fig. 2. As can be seen there is no general "best" process, it depends on the objection and user of the routing. For sure you cannot leave such a crucial decision to be taken by the process planner.

Note: for max production use alt. \#1; for min. cost use Alt. \#22; for max. profit use alt. \#9; for min. investment use alt. \# 3; for No. of years to ROI use alt. 13;

\begin{tabular}{|c|c|c|c|c|c|c|c|c|c|c|}
\hline $\begin{array}{l}\text { Aft } \\
\text { Nit }\end{array}$ & $\begin{array}{r}\text { otal } \\
\text { Coxt }\end{array}$ & $\begin{array}{l}\text { Thate } \\
\text { Thime }\end{array}$ & $\begin{array}{c}\text { Mex } \\
\text { Ttere }\end{array}$ & 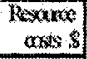 & $\begin{array}{r}\mathrm{M} \times \mathrm{i} \\
1\end{array}$ & $\begin{array}{r}3 x+4 \\
2\end{array}$ & Md & $\begin{array}{r}\text { Mati } \\
4\end{array}$ & $\begin{array}{r}\mathrm{Mdz} \\
5\end{array}$ & $\begin{array}{r}M \\
6\end{array}$ \\
\hline 1 & $23 \%$ & 54 & 53 & WOOO & 5 & & & & & \\
\hline 2 & 190 & $\mathrm{~S}^{3}$ & 63 & 309 & & 63 & & & & \\
\hline 3 & 159 & $\operatorname{En}$ & 11,0 & 3an & & & 1,13 & & & \\
\hline 4 & $24 \%$ & 1243 & 12,4 & 10000 & & & & & & 1249 \\
\hline 5 & Wo & 51 & 458 & (notol & $4 \sqrt{3}$ & & & & & 10 \\
\hline 6) & $17 \times 9$ & 894 & $5 \sqrt{2}$ & 45000 & 292 & & & & 572 & \\
\hline 7 & 281 & 710 & 300 & (10\%O) & $\sin$ & & & 133 & & \\
\hline 8 & 1057 & 699 & 589 & $700 \mathrm{mon}$ & and & 589 & & & & \\
\hline 9 & 1697 & 622 & 48 & $\therefore(1000)$ & & 483 & & & & 10 \\
\hline 10 & 155 & 919 & 572 & 3000 & & 3.17 & & & 572 & \\
\hline 11 & 1813 & 745 & 53 & 3000 & & 53 & & 19 & & \\
\hline 2 & $18 \mathrm{~s}$ & 06 & 3 & sural & & 16 & 7.3 & & & \\
\hline 13 & M8 & 124 & 69 & 90 & & & 2014 & & 5 & \\
\hline 14 & 1819 & $101 \%$ & 88 & $12 \times 3 \times 3$ & & & $n k$ & & & 16 \\
\hline $\mathrm{BS}$ & 24,9 & 13,50 & 11,20 & $n \leq x, 0)$ & & & & 150 & & 1140 \\
\hline 16 & 1609 & 1334 & 999 & $120(0)$ & & & & & 99 & 275 \\
\hline 17 & 461 & 130 & $6: 40$ & $990 \times 1$ & & & 4 & 1.3 & 3 & \\
\hline 18 & 176 & 890 & 3.58 & 1300 & 29 & & & 15 & 38 & \\
\hline 39 & 4190 & 193 & 28 & $3 / 2 \times$ & & 3 & 63 & 1.3 & & \\
\hline 20 & 43 & 108 & 27 & 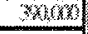 & & 3.30 & 3 & & 3,91 & \\
\hline 21 & $\mathrm{MOB}$ & 3 & 68 & 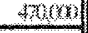 & & $a x$ & sx & & & 3 \\
\hline 2 & (13) & 107 & 38 & W & & 1.16 & 30 & 1.5 & 38 & \\
\hline
\end{tabular}

Figure 2. Alternate routing 
To demonstrate the benefits of employing the KBMS method in production scheduling, let examine the throughput of processing a product with the data given in the company road map.

The objective of production management stage is to plan the activities on the shop floor in a manner that order delivery date will be met. Thus the planning must consider: the available resources, i.e. plan with finite capacity; the product structure. The use of the product structure is to make sure that all item required for assembly will be available when needed and not before. When an item is delayed, the planning of all other dependent items must be adjusted.

The KBMS planning method is with finite capacity and with the use of the product tree [3]. The detailed capacity plan is transformed into a real schedule for the purpose of job release to shop floor. Shop floor is still free to produce the product mix by any other routing which facilitates the solution of problems caused by disruption, with the restriction that the released product mix, as specified for the period, must be completed in time.

The KBMS planning steps are as follows:

1. Stock allocation.

The allocation strategy is to assign stock to the critical order. A time base bill of materials is constructed using the CAPP program. The critical order is defined as the order whose low-level item has the start date at the earliest time. After each allocation the time base BOM is updated.

2. Adjust quantities by economic considerations

3. Capacity planning - resource loading

Capacity planning strategy is to start with the critical low level item of the critical order, from its first operation. This item has priority. Loaded operations are recorded in a Gant chart format which indicated loading status. If there is no idle time or the preferred resource, or the waiting time is too long, the road map is used to scan that operation looking for an alternate resource.

4. Job release for execution

5. Shop floor scheduling and control.

Shop floor strategy is that whenever a resource is free, it searches for a free operation. If there is a match the operation is loaded. If the resource is not the optimum for any of the free operations, a "look ahead" is used to determine the "waiting time" for a free operation. The waiting time (idle time) is used to compute a new optimum for a free operation, and load it. It is the efficiency of being in-efficient.

The decision is made by scanning the operation raw of the road map (see Fig. 1) and comparing the free resource time to the optimum resource time. This scheduling strategy was tested on: two orders; 12 items, 15 resources. The results are shown in Table 1. Fig. 3 show the two extreme detailed scheduling. 
Table 1. comparison of scheduling strategies

\begin{tabular}{lcc}
\hline Criteria of routing optimization & Number of periods to process orders & Unit cost \\
\hline Maximum production & 35 & 162 \\
Minimum cost & 32 & 76.2 \\
Semi flexible & 23 & 131 \\
The KPMS strategy & 21 & 102
\end{tabular}

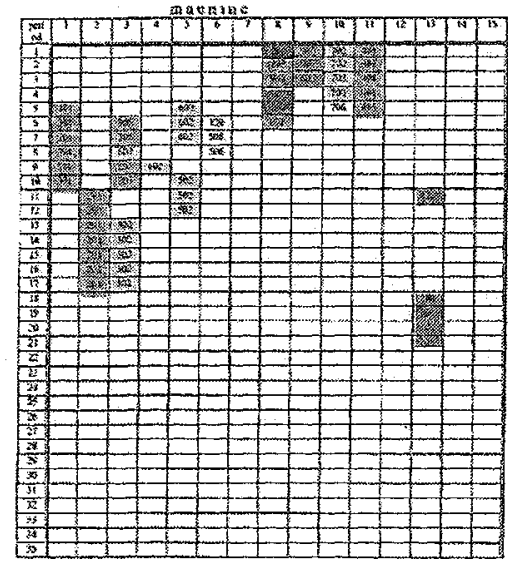

KPMS planning strategy

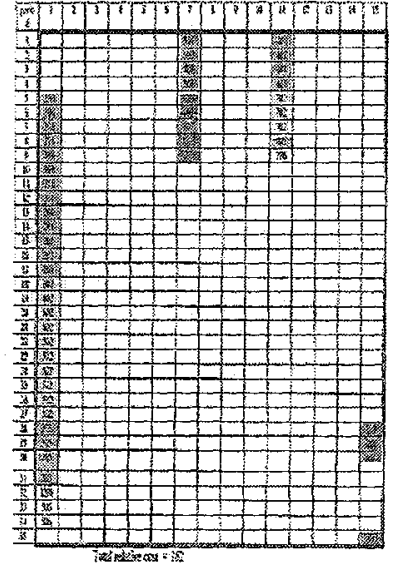

Max. production routing

Figure 3. Throughput as a function of scheduling strategy

\section{REFERENCES:}

1. Fitzgerald, A., (2000), Enterprise resource planning (ERP)-breakthrough or buzzword? In: Third International Conference on Factory 2000. Competitive Performance Through Advanced Technology (Conf. Publ. No.359). IEE, London, UK; pp.291-7

2. Guenov, M. D., (2002), Complexity and Cost Effectiveness Measures for Systems Design, Second International Conference of the Manufacturing Complexity Network, pp. $455-466$

3. Halevi, G., (1980); The Role of Computers in the Manufacturing Processes, WeilyInterscience.

4. Halevi, G., (1999): Re-Structuring the Manufacturing Process - Applying the Matrix Method, The St. Lucie/APICS Series on Resource Management.

5. Liu, J. and MacCarthy, B. L., (1996), The classification of FMS scheduling problems, International journal of production research, Vol. 34, No. 3, 647-656.

6. Tinham, B., (2000), What place MRP II in the new world? Manufacturing Computer Solutions. vol.6, no. $1 ;$ p.14-18

7. Wiendahl, H. P. and Scholtissek, P., (1994), Management and Control of Complexity in Manufacturing, Annals of the CIRP, Vol. 43/2, pp.533-540. 